\title{
Modeling Fate and Transport of Arsenic in a Chlorinated Distribution System
}

\author{
Jonathan B. Burkhardt ${ }^{\mathrm{a}}$, Jeff Szabo ${ }^{\mathrm{a}}$, Stephen Klosterman ${ }^{\mathrm{b}}$, John Hall ${ }^{\mathrm{a}}$, Regan Murray ${ }^{\mathrm{a}, *}$ \\ ${ }^{a}$ US Environmental Protection Agency, National Homeland Security Research Center, 26 Martin Luther King Dr. West, Cincinnati, OH, 45268, USA \\ ${ }^{b}$ Harvard University, Organismic and Evolutionary Biology, Cambridge, MA, USA
}

\begin{abstract}
Experimental and modeling studies were conducted to understand the fate and transport properties of arsenic in drinking water distribution systems. Pilot scale experiments were performed in a distribution system simulator by injecting arsenic and measuring both adsorption onto iron pipe material and the oxidation of arsenite by hypochlorite in tap water to form arsenate. A mathematical model describing these processes was developed and simulated using EPANET-MSX, a hydraulic and multi-species water quality software for pipe networks. Model parameters were derived from the pilot-scale experiments. The model was applied to both the distribution system simulator and EPANET example network \#3, a real-world model of a drinking water system serving approximately 78,000 customers. The model can be applied to systems-level studies of arsenic fate and transport in drinking water resulting from natural occurrences, accidental spills, or intentional introduction into water.
\end{abstract}

Keywords: fate and transport, arsenic, EPANET-MSX

\section{Introduction}

Arsenic (As) is a naturally occurring toxic material that is highly soluble and often found in water sources. ${ }^{1}$ The U.S. Environmental Protection Agency reduced maximum contaminant level (MCL) for As from $50 \mathrm{ppb}$ to $10 \mathrm{ppb}(\mu \mathrm{g} / \mathrm{L})$ in $2001 .^{2}$ This MCL reduction and the known toxicity of As have resulted in significant research into technologies to remove As from drinking water. ${ }^{3-44}$ Due to the high affinity of iron-based materials for As, many of these studies have investigated how much As adsorbs onto different iron-based materials in order to understand their viability for As removal in drinking water treatment. ${ }^{3-31,34,35,42,44}$

Iron-based pipe materials can be found in the majority of drinking water distribution systems. Cast iron, ductile iron, and steel have been used in water distribution systems for many years. While some of this infrastructure is slowly being replaced with other materials, such as cement-lined cast iron, many older pipes within a distribution network may still have exposed iron-based surfaces. Over time, these iron-based pipes corrode and can also acquire mineral deposits or biofilms. ${ }^{45-49}$ The corroded surface of iron pipes has been found to contain a mixture of different species of iron, such as amorphous ferric hydroxide, goethite, ferrihydrite, siderite, lepidocrocite, and magnetite. ${ }^{46}$ If arsenic is present in the water, it can adsorb to these iron-based pipe materials. Segments of pipes taken out of service have been found to contain elevated As levels even though only low As levels were present in the water. ${ }^{46}$

The goal of this study was to develop a predictive model of arsenic fate and transport in drinking water systems. To this

\footnotetext{
${ }^{*}$ Corresponding author

Email address: Murray.Regan@epa.gov (Regan Murray)
}

end, experimental studies were conducted to measure arsenic adsorption to and desorption from pipe walls and arsenite oxidation in chlorinated water. Cast iron coupons that were allowed to corrode in tap water were used to mimic the inner surface of pipes in older distribution systems, or where defects may have formed in newer cement-lined iron pipes. A mathematical model was developed that incorporates adsorption, desorption, advection, and reaction with chlorine. Model parameters were estimated from data collected during pilot-scale experiments. The model was simulated using EPANET-MSX, a hydraulic and multi-species water quality modeling tool, and applied to models of both a pilot scale pipe loop and a real-world drinking water system. The model is simple enough to apply to full-scale distribution system models to investigate naturally occurring arsenic or accidental contamination with arsenic species.

\section{Background}

Despite having been extensively studied, there is little agreement within the literature regarding the selection of adsorption models and associated parameters for modeling arsenic adsorption. Differences in test materials, research goals, and experimental designs have led to a wide range of numerical parameters for each adsorption model. General trends in adsorption behavior are consistent between various studies, but the interpretation of the behavior varies. Further, the species of iron involved in the adsorption process will also alter the affinity for arsenic.

A significant body of research has highlighted arsenic's affinity for iron-based materials. Pierce and Moore ${ }^{3,4}$ reported adsorption characteristics for arsenite $\left(\mathrm{As}^{3+}\right)$ and arsenate $\left(\mathrm{As}^{5+}\right)$ on 
amorphous iron hydroxide particles as well as other iron compounds. They found that arsenite has a maximum adsorption at neutral $\mathrm{pH}$ values $(\mathrm{pH} 7)$, with slight decreases at higher or lower $\mathrm{pH}$ values. Maximum arsenate adsorption occurs at low $\mathrm{pHs}$, and decreases with increasing $\mathrm{pH}$. Additionally, the adsorption behavior (concentration vs. adsorption) for arsenate was shown to be linear at high concentrations ( $>1 \mathrm{ppm} \mathrm{As})$ and follow the Langmuir isotherm at lower concentrations $(<$ $1 \mathrm{ppm}$ As). ${ }^{4}$ Arsenic adsorption on other iron-based materials has been previously fit to the Langmuir isotherm, $3,4,15,16$ the Freundlich isotherm ${ }^{7,8,26,29}$ or both ${ }^{6,19,24,27,44}$ under different experimental conditions.

The capacity of iron-based materials to adsorb As varies based on the chemical composition of the pipe material. In addition, the accessible adsorption surface area varies for each type of iron specie. Increasing the available surface area generally increases the adsorption capacity of the material. Measured surface areas of particulate forms for various materials ranges from as low as $1.16 \mathrm{~m}^{2}$ for hematite $\left(\alpha-\mathrm{Fe}_{2} \mathrm{O}_{3}\right)^{14}$ to $600 \mathrm{~m}^{2} / \mathrm{g}$ for amorphous iron hydroxide. ${ }^{12} \mathrm{~A}$ reduction in surface area was also observed as corrosion products aged. ${ }^{50}$ This wide range of experimentally reported surface areas highlights the variability in the structures of iron oxides and hydroxides.

Kinetic adsorption studies have revealed that arsenic adsorbs onto iron-based materials rapidly, within 4 hours. ${ }^{4,5,7-9,23,24,27}$ Pierce and Moore commented that the adsorption rate for arsenate was faster for higher starting concentrations. ${ }^{4}$ Pierce and Moore also speculate that there may be be multiple types of surface sites on amorphous iron hydroxide that may have differing affinities to As. ${ }^{4}$ Later studies confirmed the presence of multiple adsorption complexes containing As and iron. ${ }^{10,31,34,35}$

For this study, adsorption and reaction modeling of As in water distribution systems was performed with EPANET-MSX. EPANET-MSX $^{51,52}$ is the multi-species extension of the hydraulic simulator, EPANET ${ }^{53}$, which allows for user-defined reaction mechanisms between multiple chemical species simultaneously. EPANET and EPANET-MSX have been used to study the fate and transport of numerous substances in bulk water and on pipe walls within water distribution systems. ${ }^{51,53-60}$

Previous research by some of the authors of this paper reported on arsenate experiments conducted at the pilot-scale ${ }^{55}$ and initial mathematical model development ${ }^{54,55}$. The EPANET-MSX user's manual ${ }^{51,52}$ provides an example of the arsenite oxidation and arsenate adsorption model in a chloraminated environment. This paper presents new data from pilot-scale experiments with oxidation of arsenite to arsenate in chlorinated drinking water. The model presented herein was validated with the pilot-scale data and was applied to a larger scale distribution network in order to provide a more realistic context for application of these models. The model was developed to capture the dominant As adsorption behavior in iron-based pipe material, since it is unlikely that a utility would know the exact chemical make-up of the inside surface of the pipes and the model would become computationally intractable if individual iron species were modeled separately.

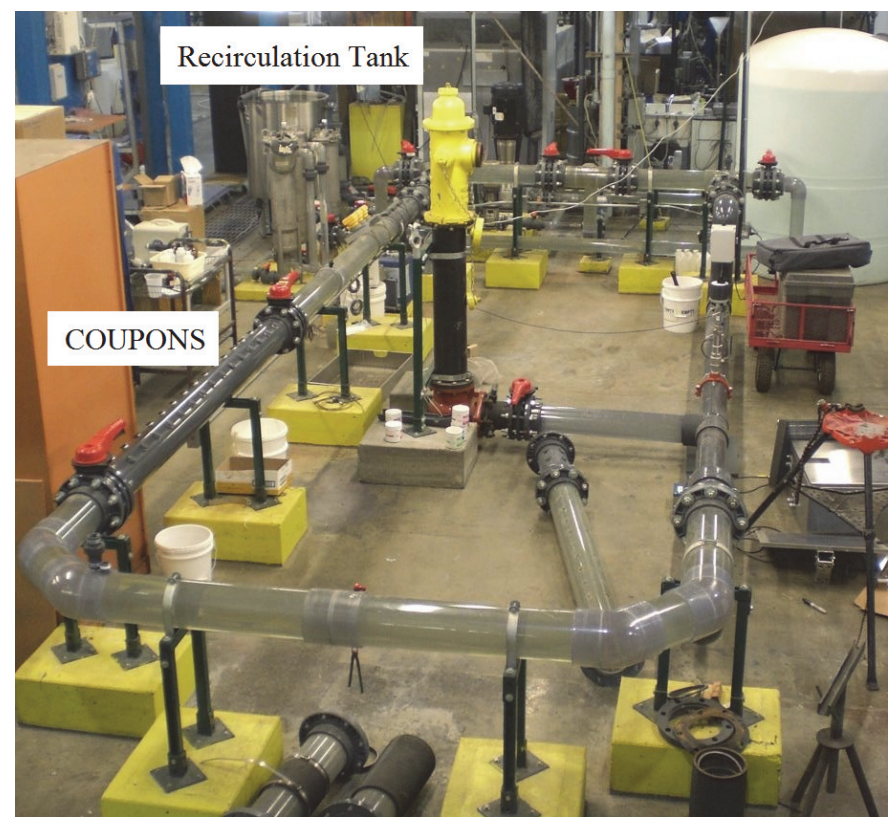

Figure 1: Image of the DSS.

\section{Material and Methods}

This study included both experimental and modeling work and methods for each are discussed here.

\subsection{Experimental Methods}

\subsubsection{Distribution System Simulator}

The Distribution System Simulator (DSS), see Figure 1, was constructed at EPA's Testing and Evaluation (T\&E) facility in Cincinnati, $\mathrm{OH}$ in 2005 to support water security research projects, focusing on the persistence and decontamination of contaminants in water distribution systems. ${ }^{61,62}$ The DSS is a pilot scale test loop constructed primarily of polyvinyl chloride (PVC) pipe. The total system volume is approximately 833 $\mathrm{L}$, and the total internal surface area is approximately $16 \mathrm{~m}^{2}$. There is approximately $23 \mathrm{~m}$ of linear pipe-consisting mainly of $15 \mathrm{~cm}$ diameter pipes, but with some 5 and $10 \mathrm{~cm}$ diameter pipes. There are three system pumps to allow for multiple flow rates. A $397 \mathrm{~L}$ stainless steel recirculation tank is in-line with the main pipe and another large tank supplies fresh tap water to the pipe loop.

One segment of pipe within the DSS contains holes that accept threaded fittings, and coupons can be inserted flush with the interior surface of the surrounding pipe to study adsorption, desorption, and presence and impact of a biofilm. Coupons can be removed periodically throughout experiments by turning off the pump, isolating the pipe section, removing the coupon and replacing it with a PVC blank. The system's flow was stopped for approximately 30 seconds during these coupon exchange. Sensors are installed in the DSS to monitor standard water quality parameters, such as, $\mathrm{pH}$, turbidity, free chlorine, total chlorine, 
specific conductivity, temperature and oxidation-reduction potential. Additionally, pressure and flow rate can be monitored continuously.

The flow rate in the DSS was maintained at $315 \pm 1 \mathrm{~L} / \mathrm{min}$ during normal operation, which equates to an approximate 1.5 minute hydraulic cycle through the system. The flow was stopped only to remove coupons. The system $\mathrm{pH}$ and temperature were approximately 8.5 and $20^{\circ} \mathrm{C}$, respectively, throughout the experiments. All sensors were calibrated prior to the experiments and were maintained according to the manufacturers' recommendations as necessary throughout. The schematic showing the injection and sample ports, recirculation tank, and coupon pipe in the DSS is shown in Figure 2. The arsenic solutions were injected in a port that was after the pump in the system. Bulk liquid samples were taken from a sample port in the pipe before the water entered the recirculation tank.

Sixty (60) small (1", $2.54 \mathrm{~cm}$, diameter) circular coupons were fabricated from cast iron pipes that had been removed from service from the Greater Cincinnati Water Works (GCWW) distribution system. Thirty (30) were installed in the DSS for each of the two experiments. The coupons provided an initial surface area of $152 \mathrm{~cm}^{2}$ onto which As could adsorb. Prior to performing each experiment the coupons were conditioned in the DSS for approximately eight weeks, which allowed the coupons to corrode and a biofilm to form in water supplied by GCWW.

\subsubsection{Coupon and Bulk Water Analysis}

Arsenic concentrations on the coupons were determined using Inductively Coupled Plasma-Optical Emission Spectroscopy (ICP-OES) using Standard Method 3120B. The minimum detection limit for ICP-OES for As is $0.006 \mathrm{mg} / \mathrm{L}$ (6 ppb). Solid samples were digested in nitric acid according to Standard Methods 3030D and 3030E ${ }^{63}$. Coupon samples were prepared by scraping the surface with a clean, sterile scalpel onto a clean pre-weighed porcelain $30 \mathrm{~mL}$ crucible. Coupons were rinsed over the crucible with deionized water to remove any residual material. Samples were dried in a $60^{\circ} \mathrm{C}$ oven for at least 24 hours, or until the samples were dry. Crucibles were cooled and reweighed to determine the mass of solids scraped from the coupons. Dry solids were digested in nitric acid and analyzed using ICP-OES. Aqueous phase arsenic concentrations were directly analyzed with ICP-OES.

In the second DSS experiment, the concentration of arsenite in aqueous samples was determined using an anion exchange column. The anion exchange column used for speciation had been treated to have an acetate surface. Arsenate in a sample is bound to the column and arsenite is able to pass through. The effluent is analyzed with ICP-OES to determine arsenite concentration. Arsenate concentrations were calculated as the difference between the total arsenic and arsenite concentrations.

A control coupon was removed immediately prior to the injection of arsenic in each experiment to establish baseline arsenic content and biofilm growth. Biofilm growth was measured using Standard Method $9215 \mathrm{C}^{63}$ to determine a heterotrophic plate count (HPC). In this method the corrosion material was scraped into $10 \mathrm{~mL}$ of sterile monopotassium phosphate buffer $(\mathrm{pH}$ 7.2). Corrosion solids were then broken up with a glass stirring rod, followed by serial dilution and plating. Arsenic concentrations found on the corrosion solids were measured as described above.

\subsubsection{Arsenate Experiment}

An arsenate stock solution was prepared by dissolving $5.26 \mathrm{~g}$ of $99 \%$ sodium arsenate dibasic heptahydrate (Sigma-Aldrich, St. Louis, MO) into $1.5 \mathrm{~L}$ of deionized water. This produced a solution with a concentration of $842(\mathrm{mg} \mathrm{As}) / \mathrm{L}$. One-liter (1 L) of the stock solution was injected into the DSS using a pressurized syringe fabricated at the T\&E facility. The injection took 31 seconds to complete. Referencing the arsenate injection as time 0 , duplicate coupons were removed at 1, 5, 15, 30, 60, $120,180,300,420,1440$ and 4320 minutes and the remaining 3 coupons were removed at 7 days ( 8640 minutes). Bulk liquid-phase samples were taken at the sample port (see Figure 2)-where $10 \mathrm{~mL}$ of water was drained into new $50 \mathrm{~mL}$ polypropylene sampling tubes. Liquid samples were taken at 4 , 8, 10, 15, 16, 17, 18, 19, 20, 22, 45, 76, 138, 199, 255, 333, 387, 439, 1447, 3013, 4340 and 8636 minutes after the injection.

\subsubsection{Arsenite Experiment}

A second DSS experiment was performed using 99\% anhydrous sodium arsenite (Sigma-Aldrich, St. Louis, MO) as the injected contaminant. A stock arsenite solution was produced with a final concentration of 1,200 (mg As)/L. The water supplied to the DSS is chlorinated, which oxidized arsenite to form arsenate following the general reaction form:

$$
\mathrm{As}^{3+}+\mathrm{HOCl} \longrightarrow \mathrm{As}^{5+}+\mathrm{Cl}^{-}
$$

The sodium arsenite injection was performed in the same way as the sodium arsenate injection. Bulk aqueous samples were taken at times 0 (immediately prior to injection), 4, 7, 8, 9, $10,11,13,15,17,19,30,60,120,180,240,300,360,420$, 1440, 2880, 4320, 5760, 10080, 14400, 20160 and 30240 minutes. Coupons were removed at 1.33, 10.25, 22.5, 39.75, 72.5, 133.167, 194.75, 317, 435, 1440, 2880, 4320, 5760, 10080, 14400, 20160 and 30240 minutes. In order to extend the length of the adsorption testing, single coupons were removed at many sample times rather than duplicates. More samples were taken in the first 30 minutes of the experiment to better capture fast oxidation of arsenite. The duration of the experiment was extended to 21 days in order to better capture the desorption of arsenic from the pipe.

\subsection{Modeling and Simulation Methods}

EPANET-MSX was used to model the fate and transport of As species within the DSS. A one-second timestep was used for hydraulic, water quality and pattern timesteps. The absolute 
and relative concentration tolerance values were set to $10^{-9}$ for the model of the DSS, and $10^{-6}$ for the model of the larger system [Net3] (systems discussed further below). The fifth-order Runge-Kutta integrator was used for all simulations.

\subsubsection{Adsorption Model and Parameter Estimation}

The adsorption model used within this study was the Langmuir isotherm. The Langmuir isotherm is capable of modeling both adsorption and desorption of a chemical specie. The Langmuir isotherm assumes mono-layer adsorption on a smooth surface. The adsorption rate equation for the Langmuir isotherm ${ }^{55}$ is:

$$
\frac{d\left[A s^{5+}\right]_{w}}{d t}=\frac{\left[A s^{5+}\right]_{a q}\left(S_{\max }-\left[A s^{5+}\right]_{w}\right)-K_{e q}\left[A s^{5+}\right]_{w}}{\frac{1}{k_{1}}+\frac{1}{k_{f}}\left(S_{\max }-\left[A s^{5+}\right]_{w}\right)}
$$

where $d\left[A s^{5+}\right]_{w} / d t$ is the rate of arsenic adsorption onto the coupon material $\left(\mathrm{mg} /\left(\mathrm{m}^{2} \cdot \mathrm{min}\right)\right),\left[A s^{5+}\right]_{a q}$ is the bulk water arsenate concentration $(\mathrm{mg} / \mathrm{L}), S_{\max }$ is the maximum adsorbance density $\left(\mathrm{mg} / \mathrm{m}^{2}\right),\left[A s^{5+}\right]_{w}$ is the adsorbed arsenate density $\left(\mathrm{mg} / \mathrm{m}^{2}\right), k_{1}$ is the adsorbance rate constant $(\mathrm{L} /(\mathrm{mg} \cdot \mathrm{min})), K_{e q}$ is the equilibrium constant $(\mathrm{mg} / \mathrm{L})$, and $k_{f}$ is the mass transfer coefficient $\left(\mathrm{L} /\left(\mathrm{m}^{2} \cdot \mathrm{min}\right)\right)$.

\subsubsection{Arsenic Fate and Transport Model}

The change in the bulk water concentration of arsenic during the DSS experiment was modeled as:

$$
\begin{aligned}
\frac{d\left[A s^{5+}\right]_{a q}}{d t}=- & \frac{1}{r_{h}} \frac{\left[A s^{5+}\right]_{a q}\left(S_{\max }-\left[A s^{5+}\right]_{w}\right)-K_{e q}\left[A s^{5+}\right]_{w}}{\frac{1}{k_{1}}+\frac{1}{k_{f}}\left(S_{\max }-\left[A s^{5+}\right]_{w}\right)} \\
& -v \frac{d\left[A s^{5+}\right]_{a q}}{d x}+k_{o x}[H O C L]\left[A s^{3+}\right]_{a q}
\end{aligned}
$$

where $d\left[A s^{5+}\right]_{a q} / d t$ is the rate of change of arsenate concentration in the bulk water $(\mathrm{mg} /(\mathrm{L} \cdot \mathrm{min})), t$ is time $(\mathrm{min}), r_{h}$ is the hydraulic radius $\left(\mathrm{L} / \mathrm{m}^{2}\right), v$ is velocity, and $x$ is the longitudinal distance. ${ }^{64}$ Here, $k_{o x}$ is the oxidation rate constant and [HOCL] is the concentration of hypochlorite. The oxidation rate for arsenite to arsenate in a chlorinated system was taken from Dodd et al. ${ }^{33} k_{o x}=1.56 \times 10^{7}(\mathrm{~L} /(\mathrm{mol} \cdot \mathrm{min}))$.

The mass transfer coefficient was calculated by EPANET-MSX for each pipe in the model, using an empirical relationship for turbulent flow through a circular pipe ${ }^{65}$, as follows,

$$
k_{f}=0.026 \frac{D}{d}\left(\frac{d v^{0}}{v}\right)^{0.8}\left(\frac{v}{D}\right)^{1 / 3}
$$

where $k_{f}$ is the mass transfer coefficient, $d$ is the pipe diameter, $D$ is the diffusion coefficient, $v^{0}$ is the average velocity and $v$ is the kinematic viscosity.

The rate of change in the chlorine concentration was modeled as follows:

$$
\frac{d[H O C L]}{d t}=-k_{o x}\left[A s^{5+}\right]_{a q}[H O C L]
$$

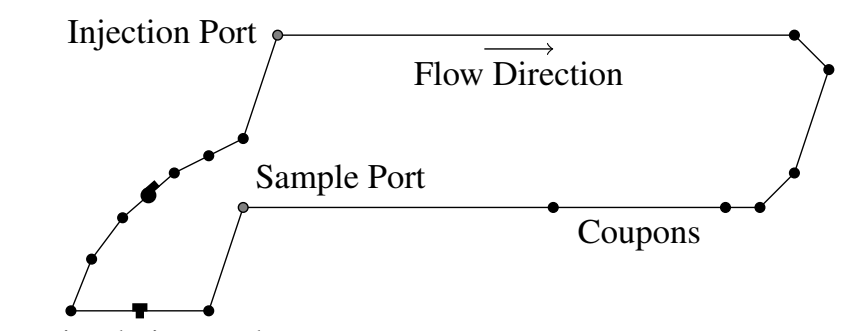

Recirculation Tank

Figure 2: Diagram of the DSS network as visualized in EPANET.

The value of $S_{\max }$ was selected to be $500 \mathrm{mg} / \mathrm{m}^{2}$ based on analysis of adsorption capacities found in the literature ${ }^{3-44}$, corrosion product masses from the DSS experiments and expected iron species found on similar pipes ${ }^{46}$. . The value of $k_{1}$ was fit to data from both arsenate and arsenite DSS experiments by simulating with EPANET-MSX. The value of $k_{1}$ was varied for each simulation and the results were compared to experimental results for each DSS experiment. The value of $\mathrm{K}_{e q}$ was set to $0.0539 \mathrm{mg} / \mathrm{L}$ for As on iron oxide materials that was reported by Pierce and Moore. ${ }^{4}$ A simulation focused on desorption alone was conducted used the maximum wall concentration measured in the arsenite experiment and comparing this model to the last three days of the arsenite experiment to ensure that desorption was being modeled well.

\subsubsection{Simulation using EPANET-MSX}

An EPANET ${ }^{53}$ model of the DSS was simulated using EPANET-MSX ${ }^{51,52}$ using equations $1-4$ to model changes in arsenic species within the system. Figure 2 shows the graphical representation of the EPANET infrastructure model of the DSS. Flow through the pipes was in the clockwise direction (as shown).

The modeled version of the DSS loop excludes bypass pipes and no-flow zones and thus has a slighter smaller system volume of approximately $805 \mathrm{~L}$ and internal surface area of approximately $14.5 \mathrm{~m}^{2}$. In the modeled system, adsorption of arsenic was restricted to only a small pipe that corresponds to the location of the coupons in the real system (see Figure 2). The simulated coupon pipe in the EPANET-MSX model was specified to have a pipe length of $0.0286 \mathrm{~m}$. This length results in a surface area of that pipe equal to the surface area of 27 coupons (those present at the beginning of the injection experiments). The infrastructure model is fixed in EPANET-MSX and therefore was not able to account for the decreasing area available for adsorption that was the result of coupon removal in the DSS experiment. The initial wall concentration of arsenic was set to $20 \mathrm{mg} / \mathrm{m}^{2}$ for both experiments to match the coupon samples taken after 1 minute in both DSS experiments (discussed further in the Results and Discussion section). 


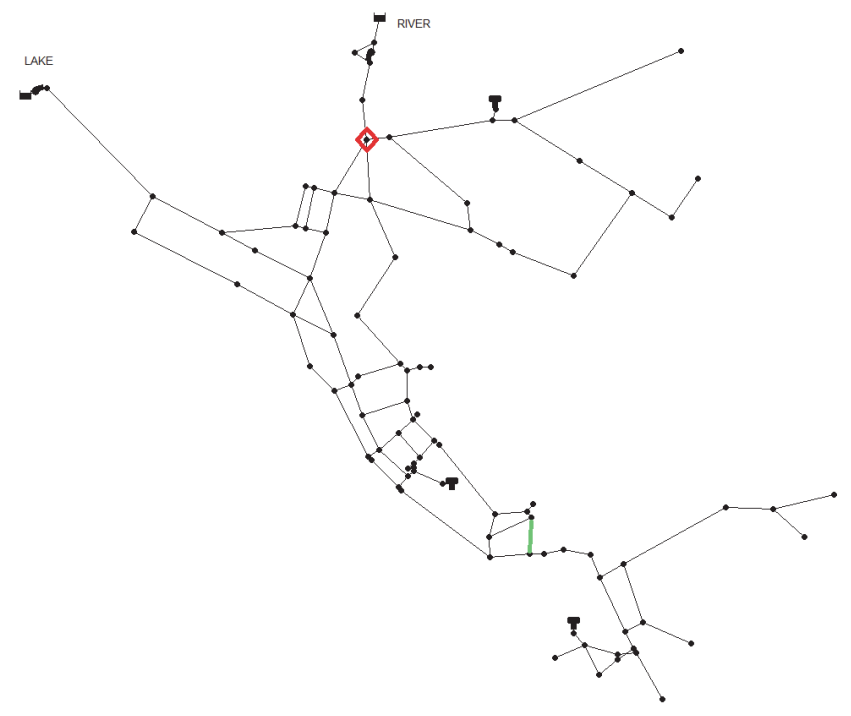

Figure 3: Network 3 Diagram. Injection location is shown with a red diamond. Pipe \#249 highlighted in green. The diagram contains a river source, lake source, 3 tanks, 2 pumps, 92 junctions and 119 pipes.

\subsubsection{Network 3 Example}

To demonstrate the impact of As adsorption and desorption in a large scale network, the parameters listed in Table 1 were used to simulate an arsenite injection in the EPANET example network \#3 (Net3, see Figure 3). Net3 models a 15 MGD system serving approximately 78,000 people and contains 92 nodes, 119 pipes, 2 sources and 3 tanks. The average residence time in the network is 13.5 hours and the maximum residence time is 130 hours. A 6-hour arsenite injection was simulated to occur at a rate of $1 \times 10^{6} \mathrm{mg} / \mathrm{min}$ at node $121 \mathrm{in} \mathrm{Net3}$ on day 1 at noon, with a total simulation time of 505 hours (21 days). The network had an initial chlorine concentration of $2 \mathrm{mg} / \mathrm{L}$, and each of Net3's two sources were set to supply $2 \mathrm{mg} / \mathrm{L}$ throughout the simulation. Simulations were performed with and without arsenate adsorption onto the pipe walls to investigate how much longer arsenic species remain in the network at aqueous concentrations exceeding the MCL of $10 \mathrm{ppb}(\mu \mathrm{g} / \mathrm{L})$ when arsenic adsorbs and desorbs from pipe walls. The initial adsorbed density of arsenic on the wall of the Net3 example was $0 \mathrm{mg} / \mathrm{m}^{2}$. All pipes within Net3 were assumed to be iron based and were considered able to adsorb As. The demand schedule and other controls in the Net3 example were extended on a 24 hour cycle to create a 505 hour input file.

\section{Results and Discussion}

The predictive model (equations 1-4) utilized three values that were determined experimentally under similar conditions $(\mathrm{pH}$ 8 , room temperature) were selected from the literature. Pierce and Moore reported a value for the equilibrium constant for arsenate, $K_{e q}$, of $0.0539 \mathrm{mg} \mathrm{As} / \mathrm{L}$ for iron oxide in water at pH 8 (reported as $0.719 \mu \mathrm{M} / \mathrm{L}$ ). ${ }^{4}$ Tanaka et al. reported the arsenate diffusion coefficient as $7.27 \times 10^{-6} \mathrm{~cm}^{2} / \mathrm{s}$. ${ }^{66}$ Dodd et al. reported the rate of oxidation for arsenite in systems with hypochlorite as $1.56 \times 10^{7}(\mathrm{~L} /(\mathrm{mol} \cdot \mathrm{min}))($ reported as 2.6 $\times 10^{5}(\mathrm{~L} /(\mathrm{mol} \cdot \mathrm{s})) .{ }^{33}$ Further, a value of $S_{\max }$ was set to 500 $\mathrm{mg} / \mathrm{m}^{2}$. See Supplemental Information for more information on how the value of $S_{\max }$ was selected. Selecting a value for $S_{\text {max }}$ ensured that the high affinity of As for iron-based materials was reflected in the model.

\subsection{DSS Experiments}

Immediately prior to As injection during the arsenate experiment the control coupon was found to have a surface concentration of 2.9 (mg As) $/ \mathrm{m}^{2}$, despite source water with As levels below the detection limit. This finding is consistent with those from other researchers that found high levels of surface accumulation of As, despite relatively low concentrations of source water. ${ }^{46}$ Biofilm density on the coupon, as measured by HPC, was measured to be $720 \pm 110 \mathrm{CFU} / \mathrm{cm}^{2}$. The mass transfer coefficient, $k_{f}$, was calculated by EPANET-MSX using equation 3 to be $0.43\left(\mathrm{~L} /\left(\mathrm{m}^{2} \cdot \mathrm{min}\right)\right)$ within the pipe containing the coupons.

Table 1 contains the parameters used within EPANET-MSX to model As dynamics for both arsenate and arsenite injections. The values of the diffusion coefficient, $D$, oxidation rate, $k_{o x}$, and equilibrium coefficient, $K_{e q}$, were selected from the literature. The value of $S_{\max }$ was selected to be consistent with previous experimental adsorption values ${ }^{3-44}$, described above, and $k_{1}$ was adjusted until model results matched those measured during the DSS experiments.

Table 1: EPANET-MSX Model Parameters

\begin{tabular}{rccl}
\hline Parameter & Value & Unit & Citation \\
\hline$k_{1}$ & 0.0004 & $\mathrm{~L} /(\mathrm{mg} \cdot \mathrm{min})$ & \\
$K_{e q}$ & 0.0539 & $\mathrm{mg} / \mathrm{L}$ & 4 \\
$S_{\max }$ & 500 & $\mathrm{mg} / \mathrm{m}^{2}$ & \\
$k_{\text {ox }}$ & $1.56 \times 10^{7}$ & $\mathrm{~L} /(\mathrm{mol} \cdot \mathrm{min})$ & 33 \\
$D$ & $7.27 \times 10^{-6}$ & $\mathrm{~cm}^{2} / \mathrm{s}$ & 66 \\
\hline
\end{tabular}

\subsubsection{Arsenate Results}

Figure 4 shows the results of the DSS arsenate experiment in terms of bulk arsenate concentration (4a) and the adsorbed arsenate concentration (4b). Arsenate concentrations throughout the arsenate injection experiment are shown in Figure 4a. Liquid samples taken from the sample port are marked with a symbol (' $x$ ') and modeled concentrations for the node that represents the sample port are shown as a solid line. Both modeled and experimental results show the system had reached a mixed state after approximately 20 minutes. Essentially no detectable As was present in the system after 1 day. This is a result primarily due to dilution because water was removed from the system at $3 \mathrm{~L} / \mathrm{min}$, and it was replaced with fresh water with no detectable As. Approximately $0.11 \%$ of the injected arsenate was calculated to have adsorbed onto the coupons, suggesting that for this system adsorption has little impact on the observed bulk 


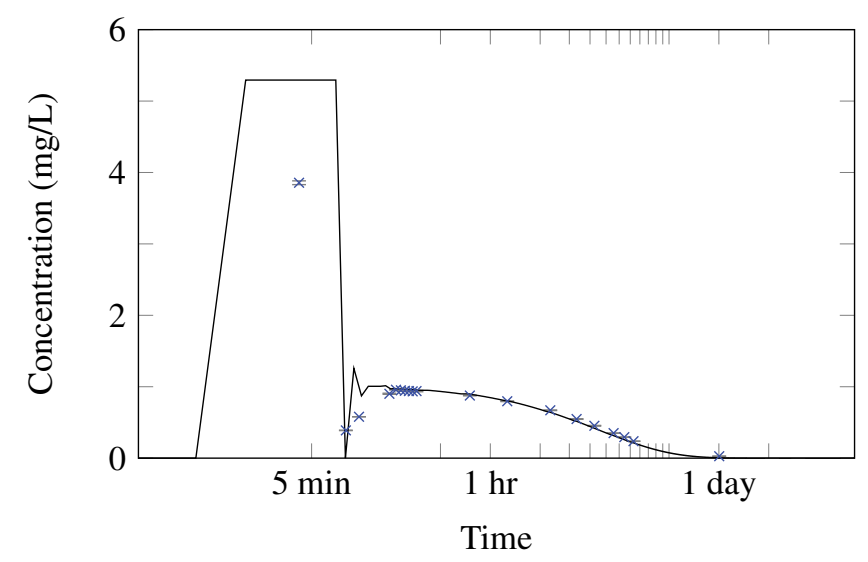

(a) Solution Concentration

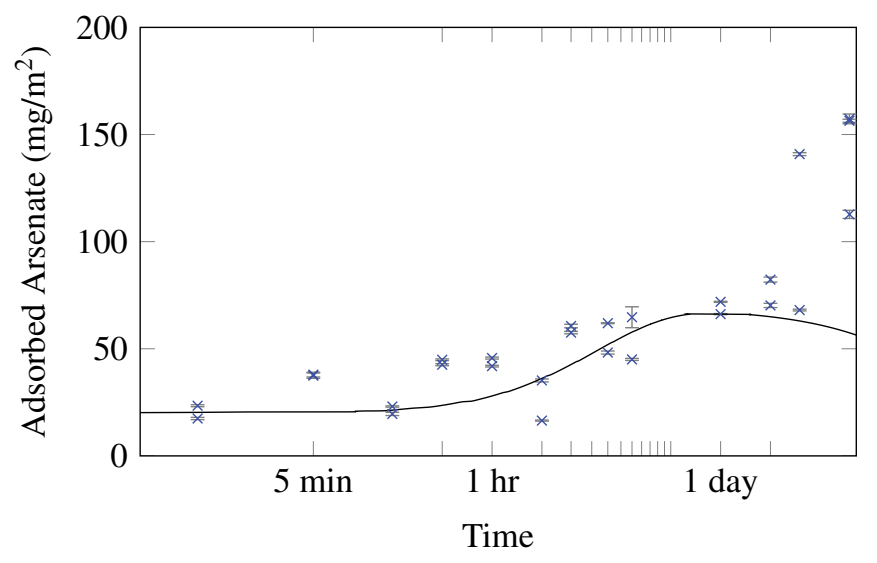

(b) Adsorbed Concentration

Figure 4: (a) Arsenate concentration in bulk, (mg As)/L, measured at the sample port of the DSS (see Fig. 2). (b) Adsorbed arsenate for DSS experiment after sodium arsenate injection. Experimental As concentration and adsorbed As data is marked with a ' $\times$ '. Modeled adsorption using parameters from Table 1 are is shown as a solid line. Error bars represent the standard deviation of measurement device.

concentration change. This was because only a small percentage of the DSS surface area (i.e., the 27 coupons) was expected to be active in the As adsorption process during experiments.

Figure $4 \mathrm{~b}$ shows the adsorbed density throughout the arsenate injection experiment. Experimental results are marked with a symbol (' $x$ ') and the modeled behavior is marked as a solid line. An initial wall adsorbed density was selected to be 20 $\mathrm{mg} / \mathrm{m}^{2}$ to match the coupon samples taken at 1 minute in both experiments.

Modeled adsorbed As densities within the first two days matches the experimental samples well. The modeled arsenate solution concentration drops to approximately zero $(<1$ $\mathrm{ppb}$ ) one day after the injection, while the experimental samples show concentrations on the order of $10 \mathrm{ppb}$. This absence of arsenate in the modeled system reduces the driving force for adsorption, suggesting that there should not have been increasing adsorption after 24 hours - at least not to the degree that was observed. It is unclear why the last five coupons had adsorbed densities exceeding $100 \mathrm{mg} / \mathrm{m}^{2}$. Arsenic may have re- mained longer in the DSS due to mixing in dead-zones (or noflow zones) or have adsorbed onto then desorbed from the PVC piping or have been retained in the biofilm which were not modeled by EPANET-MSX. The model results predicted an order of magnitude lower aqueous As, which would have resulted in much lower predicted adsorption during that period. Additionally, the actual active surface area for adsorption decreases due to removal of cast iron coupons, which was not modeled in the EPANET-MSX model, which could affect adsorption behavior. However, since similar behavior was not observed during arsenite experiments (see Section 4.1.2) the last five coupons were not used in the fitting process. The continued adsorption observed during the arsenate experiment does suggest that even low concentrations of As ( $\sim 10 \mathrm{ppb}$ or below) can continue to adsorb due to the high affinity for iron.

\subsubsection{Arsenite Oxidation}

The arsenite injection experiment was assumed to follow a twostage process; oxidation of arsenite to arsenate caused by a reaction with hypochlorite, followed by adsorption of arsenate onto the cast iron surface. A three week experiment was conducted in the DSS to investigate both the adsorption and the desorption process. The parameters listed in Table 1 were used to model this reaction and adsorption process.

Figure 5 shows the results of the arsenite experiment. Figure 5a contains the concentration profiles for arsenate (green), arsenite (red), chlorine (black) and total arsenic (blue) for both experimental (symbols) and modeled results (solid lines).

Similar to the arsenate experiment results, the initial slug corresponding to the injection can be observed. Examination of the data reveals four distinct regimes of behavior. Immediately following the arsenite injection, both arsenite and chlorine (in the form of hypochlorite) were rapidly consumed in the oxidation reaction; this process occurred within the first ten to twenty minutes after injection, which corresponds to the time it takes for the arsenite to completely mix within the DSS and consume the available chlorine. The apparent oxidation rate during the period following chlorine consumption was limited by how much new chlorine was added from the make-up water. Fresh tap water containing $0.68 \mathrm{mg} / \mathrm{L}$ chlorine at a rate of $3 \mathrm{~L} / \mathrm{min}$ was added to the system - this fresh chlorine was rapidly consumed. Complete consumption of arsenite had taken place after approximately two hours. Throughout this period, the concentration of arsenate was constant-arsenate concentration loss from the overflow in the tank was approximately equal to arsenate generation from the oxidation reaction. Following the consumption of arsenite, arsenate was the only As specie present and was lost from the system to the overflow process; no arsenic exists in solution after one day. Similar to the arsenate experiment, the model reaches very low arsenate concentrations earlier than those measured from the sample port in the DSS.

Arsenic was being adsorbed throughout these first three time periods. The final period consisted of arsenic desorption. After the first day, essentially no arsenic was present in the aqueous 


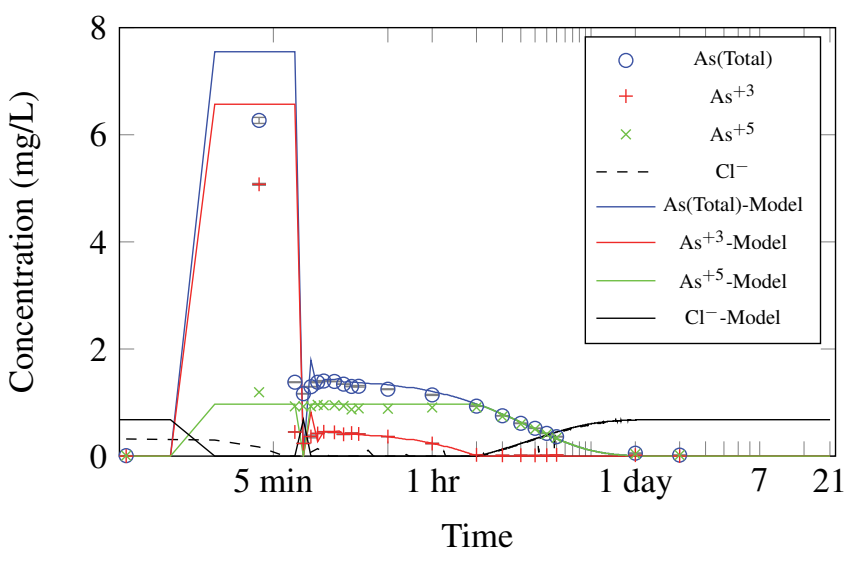

(a) Solution Concentration

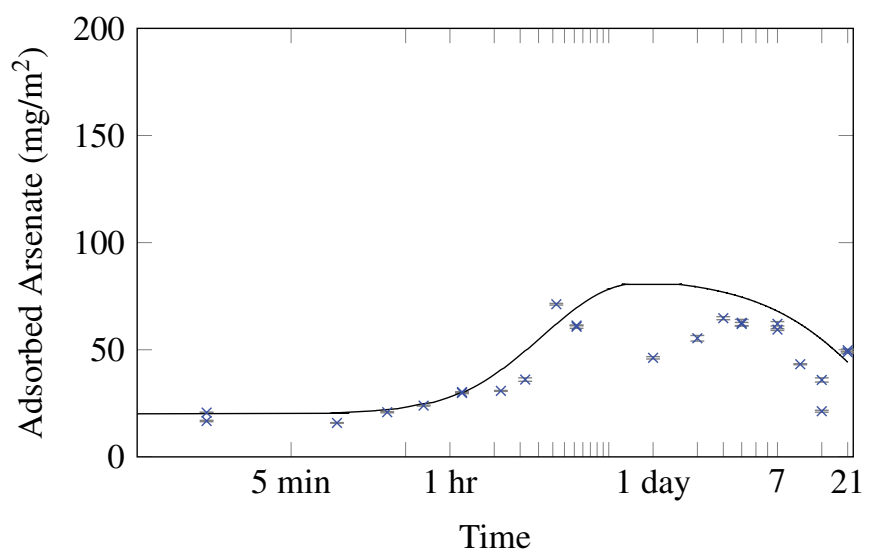

(b) Adsorbed Concentration

Figure 5: (a) Concentrations of species in bulk, $\mathrm{mg} / \mathrm{L}$, measured at the sample port of the DSS (see Fig. 2). Blue ' 0 ' indicate total arsenic, green ' $x$ ' indicate arsenate, red ' + ' indicate arsenite and the dashed black line indicates chlorine concentrations. Solid lines corresponding to these colors indicate the modeled concentrations of that specie. Error bars represent the standard deviation of experimental measurements. (b) Arsenate adsorption during the sodium arsenite DSS experiment. Experimental measurements are marked with an ' $x$ ' and modeled results are shown as a solid line. Error bars represent the standard deviation of measurement device.

phase, which results in desorption of As from pipe surfaces. Unlike during the arsenate experiment, no continued As adsorption was observed after the first day, when As levels in solution had essentially approached non-detectable levels.

Figure $5 \mathrm{~b}$ shows arsenic adsorption density throughout the arsenite injection experiment. Similar to the arsenate experiment, less than $0.1 \%$ of the injected arsenic adsorbed to the coupons' surfaces. It was assumed that arsenate was the dominant specie adsorbed for two reasons: the majority of the arsenite was oxidized quickly within the system and arsenite has a higher mobility within aqueous systems. ${ }^{67}$

Figure 6 shows the desorption period of the arsenite experiment beginning on day 3. A simulation was performed with a starting wall concentration of $65 \mathrm{mg} / \mathrm{m}^{2}$ to replicate the maximum wall concentration observed during the arsenite experiment. In order to be consistent with Figure 5b, the $x$-axis starts at 3 days.

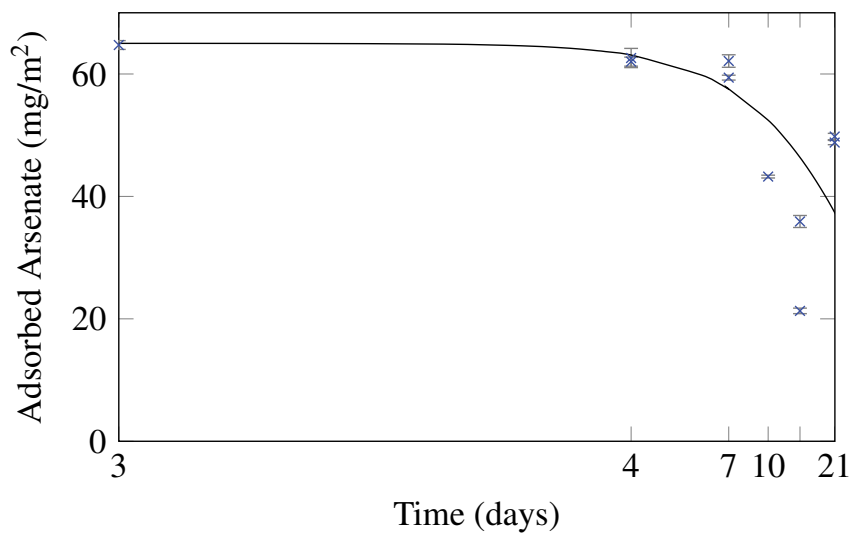

Figure 6: Adsorption density profile of arsenic desorption. Experimental measurements marked with a ' $x$ ' and modeled adsorption is indicated by a solid line. Error bars represent the standard deviation of measurement device.

Model times were adjusted by 3 days (4,320 minutes) to align the desorption model with the final 18 days of experimental results. Modeled desorption agreed well with the coupon measurements. Desorption times of As from goethite was previously reported to take between 45 minutes to 7 months to occur. ${ }^{13}$ Extending the time frame of a simulation suggests that it would take approximately a year to completely desorb As if the entire surface of the DSS had a contamination level of 65 $\mathrm{mg} / \mathrm{m}^{2}$. Desorption of As from only the coupon surface area would take approximately 6 months. These time frames are consistent with the high bonding affinity of As for iron-based materials and kinetics reported previously $3-44,46,49,68,69$.

In reporting the adsorption behavior, it was stated above that neither injection experiment adsorbed more than $1 \%$ of the injected material onto the coupons. It is important to remember that this is an artifact of the available adsorption surface in the DSS, which only contains a small active surface area of thirty 1-inch diameter coupons. If all of the surface was treated as being iron-based, the maximum adsorbed density would have reached approximately $40 \mathrm{mg} / \mathrm{m}^{2}$ of As, which translates to approximately $430 \mathrm{mg}$ of As adsorbed on the walls of the DSS (not shown). This maximum modeled wall concentration was lower than measured in the experiments, however more total mass would have been adsorbed to the much larger pipe surface area. The increased available surface area would lower the bulk As concentration faster, and subsequently reduces the driving force for adsorption faster. In this example, approximately one third of the injected As would have adsorbed to the pipe walls.

Comparing the model to experimental results shows good agreement with both experiments. However, continued adsorption of As onto the coupons beyond 1 day was observed in both DSS experiments (Figures $4 \mathrm{~b}$ and $5 \mathrm{~b}$ ). After 1 day, the modeled concentrations within the DSS were on the order of $10^{-3} \mathrm{mg} / \mathrm{L}$, whereas the experimentally measured concentrations were on the order of $10^{-2} \mathrm{mg} / \mathrm{L}$. This suggests that mass was retained in the DSS longer than was being predicted by the model. This material retention may be caused by: slower mixing or mass transport within pipes and tanks; adsorption 
and desorption from non-coupon DSS surfaces; or, diffusion or mixing of water into no-flow or dead-zone segments of the DSS. Adsorption densities in the arsenate experiment (see Figure $4 b$ ) are 2-3 times higher in the final 5 coupons relative to the coupons removed after 1 day. The same behavior was not observed to the same extent in the arsenite experiment (see Figure $5 b$ ). For this reason, no attempt was made to fit the model to the final 5 coupons taken from the arsenate experiment. $\mathrm{Pa}$ rameters that were able to produce modeled adsorptions that fit those coupons overestimated adsorptions for earlier times.

The discrepancies in model results may be related to variability in the composition of the corrosion materials on the surface of the pipes, loss of corrosion material from the coupon surface throughout the experiment, variability in biofilms on coupon surfaces, or the nature of the adsorption process that is occurring in each system. The biofilm may enhance adsorption of As on the PVC, or provide a barrier to adsorption onto the coupons. No attempt was made to model adsorption of As on PVC in this study; however, adsorption, and subsequent desorption, of As on PVC may explain the further adsorption behavior that was witnessed in experimental results. This behavior was not observed in the arsenite experiment, so it is possible that these high As densities resulted from differences in surface characteristics found on those coupons. Previous DSS experiments revealed some arsenic adsorbance on PVC blanks at various flow rates, however, this adsorption behavior was not consistently observed. ${ }^{61}$

Previous pipe sampling work ${ }^{46}$ highlights that As has been found to be adsorbed to distribution pipes in systems with low concentrations of As in the bulk water. Those findings support iron's high affinity for As, and highlights that a more permanent chemisorption process may also be involved in As adsorption. It is possible that if As were to adsorb to the PVC (or other system components), the subsequent desorption process may not be detectable with the current analytical method but could continue to adsorb to the cast iron.

The model presented herein assumed that arsenite did not adsorb to the coupon surface. Dixit and Hering ${ }^{12}$ showed that arsenite did not have a lower affinity (or higher mobility) within their tests, suggesting that it could compete with arsenate in the adsorption process. Both species of As have high affinities for iron, but arsenate is present in the system much longer than arsenite, and residual chlorine may remain on the coupon surface, oxidizing any arsenite during the period when arsenite is still present in the bulk phase. The modeled behavior in Figure $5 \mathrm{~b}$ reveals that the arsenate-only adsorption matches experimental values, suggesting arsenite adsorption may not have played a role in these experiments. Additionally, no speciation of adsorbed As was performed during these experiments, which prevented modeling arsenate and arsenite adsorption separately. Further experiments are needed to accurately determine if arsenite would play a role in adsorption if it were present in excess in the system after chlorine is depleted, or in unchlorinated systems.

Selection of an initial wall density of $20 \mathrm{mg} / \mathrm{m}^{2}$ was done so that the model would better match long term behavior. Coupons taken early in both experiments were exposed to mostly clean water followed by the brief high concentration of the initial slug related to the injection. Due to the higher concentration of the slug, the initial kinetics of adsorption was expected to be fast, but also brief.The initial transient period related to the initial slug of material was not captured perfectly in the model. Although the experimental stop and restart periods were included in the model, not including an initial wall density resulted in faster adsorption and desorption kinetics overall, which did not match experimental data from later coupons. This initial value was selected to account for experiment specific conditions and should not be necessary for larger systems. The values presented in Table 1 capture longer term behavior associated with As adsorption.

This work set out to use experimental data to generate a simple model for arsenite oxidation and arsenate adsorption in ironbased water distribution networks using hypochlorite. Literature values for some parameters were used where possible, and remaining parameters were fit to the experimental data. Previous works from Klosterman et al. ${ }^{54,55}$ discuss models generated based on the arsenate experiments used herein, and the EPANET-MSX user's manual ${ }^{51}$ provides a model for arsenite oxidation in a chloraminated system and arsenate adsorption. The arsenite injection discussed above provided data about longer term desorption behavior that was not available for previous models. The model and parameters discussed herein yielded model values that were consistent with experimental data collected in both the arsenate and arsenite experiments and can be used to model long term adsorption and desorption processes within chlorinated water distribution networks.

\subsection{Network 3 Example}

In order to better understand how this model might be applied to evaluate the behavior of As in a larger system, a 6-hour injection with a rate of injected arsenite of $1 \times 10^{6} \mathrm{mg} / \mathrm{min}$ was simulated to have occurred at node 121 in Net3 $3^{53}$ (see Figure 3 ). The simulation ran for 505 hours ( 21 days). The features of this simulation were selected to replicate an intentional introduction of As at a node in Net3, rather than naturally occurring As. This example set out to highlight the impact of modeling adsorption on the behavior and persistence of As within a fullscale water distribution system.

The simulation results showed that the contamination spread rapidly through the majority of the network, and most customer nodes ( 82 of the 92 total) exceeded the As MCL of $10 \mathrm{ppb}$ at some point during the 21 day simulation. Arsenite rapidly oxidized to arsenate, and arsenate adsorbed to most of the 119 pipes in the network. After 21 days, 104 of the pipes still had wall concentrations exceeding $1 \mathrm{mg} / \mathrm{m}^{2}$ and a total mass of $3.37 \times 10^{6} \mathrm{mg}$ As remained on the pipe walls. As desorption returned arsenic to the bulk water, many customer nodes exceeded the MCL long after the initial slug of contamination had passed through the network. These results show that arsenic 


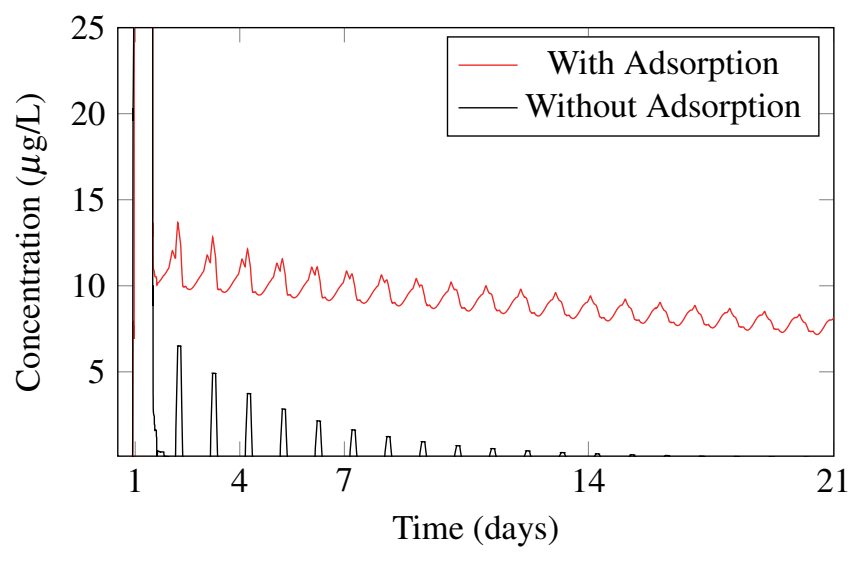

Figure 7: Concentration of arsenic present in pipe \#249 in Net3 through time. The red line represents the concentration of As in pipe \#249 when adsorption was modeled, and the black line when adsorption was not modeled.

can persist in real water distribution systems for long periods of time, and can result in exposure to harmful levels of As.

An example of the persistence of As observed in the Net3 simulations is shown in Figure 7. Figure 7 shows the bulk concentration of total As within pipe \#249 through time (highlighted in green in Figure 7). This pipe is located in the lower portion of the network, which experiences lower flow rates and does not experience the dilution effect which occurs in pipes closer to the system's sources. The red line indicates the concentration profile through time when adsorption onto pipes in the system was modeled and the black line when adsorption was not modeled. The initial slug of As travels through pipe \#249 starting on day one and ending on day 2 of the simulation. The periodic peaks in both lines are caused by water being supplied from the contaminated tanks in the system. This result highlights that if a tank becomes contaminated it too will increase the duration that a contaminant will remain in the system. Only the initial slug results in a concentration that exceeds the MCL when adsorption is not modeled. In contrast, when adsorption is modeled the concentration in the pipe still contained peak concentrations above the MCL up to 11 days after the injection. The adsorbed wall concentration of pipe \#249 exceeds $80 \mathrm{mg} / \mathrm{m}^{2}$ at the end of the 505 hour simulation, having reached a maximum concentration of approximately $91 \mathrm{mg} / \mathrm{m}^{2}$ during the passage of the initial slug. This shows the importance of modeling adsorption in order to better predict fate and transport of contaminants in water distribution systems. Such modeling could be used to assess exposure to contaminants, or evaluate decontamination strategies (e.g. altering $\mathrm{pH}$ to increase desorption or flushing to remove contaminants).

\section{Conclusion}

Experiments were conducted within a DSS to quantify adsorption and desorption of As onto iron pipe coupons and oxidation of arsenite in a chlorinated system. Results from these experiments were used to develop a general model for EPANET-MSX that could be applied to larger water distribution systems of any size. The adsorption and desorption model described herein was able to predict the adsorption and subsequent desorption of arsenic onto iron-based pipe materials. Previously reported arsenite oxidation rates were also found to be consistent with experimentally recorded behaviors. The general model described herein is simple enough to be applied to larger scale systems without becoming computationally intractable, while providing a good prediction of fate and transport of arsenic species for iron-based distribution networks.

Applying this model to a larger system demonstrated that the adsorption of arsenic species onto pipe walls prolonged the presence of arsenic at higher levels within a water distribution network. Approximately one-third of the nodes in Net3 received water that had bulk arsenic concentrations which peaked above the maximum contamination level for approximately one week longer when adsorption and desorption were considered than if no adsorption occurred. These results highlight the importance of considering adsorption when modeling the fate and transport of As within water distribution networks.

Future work will include using EPANET-MSX to model the fate and transport of other contaminants of concern in water distribution systems.

\section{Acknowledgments and Disclaimer}

The U.S. Environmental Protection Agency through its Office of Research and Development funded and collaborated in the research described here under an Interagency Agreement with the Department of Energy's ORISE fellowship program and Contract EP-C-09-041 with Shaw Environmental. It has been reviewed by the Agency and approved for publication but does not necessarily reflect the Agency's views. No official endorsement should be inferred. EPA does not endorse the purchase or sale of any commercial products or services. The authors would like to acknowledge Greg Meiners, Tim Kling, Tim Gray, and Shekar Govindaswamy for their assistance with the experiments.

\section{Supplemental Information}

Adsorbance densities in this paper have the units $(\mathrm{mg} \mathrm{As}) /\left(\mathrm{m}^{2}\right.$ pipe surface area), which was simplified to $\mathrm{mg} / \mathrm{m}^{2}$. Previously reported maximum adsorbance densities were commonly reported as (mg As)/(g Fe) (or molar equivalents), (mg As)/(g adsorbent), or (mg As) $/\left(\mathrm{m}^{2}\right.$ adsorbent surface area). The adsorbent's surface area was typically reported from BET isotherm experiments, with units of $\mathrm{m}^{2} /(\mathrm{g}$ adsorbent). In order to more easily model adsorption within larger systems, adsorbance densities related to pipe surface area, rather than sorbent surface area, were needed. In order to convert between literature values and the $S_{\max }$ presented in this work, a factor was calculated based on experimental results. This factor was calculated by 
dividing the mass of non-arsenic material in the corrosion material collected from each coupon (average $=0.3268 \pm 0.0537$ $\mathrm{g})$ by the area of a coupon (1" diameter $\left.=5.067 \mathrm{E}-4 \mathrm{~m}^{2}\right)$ to get $645.0 \pm 106.0$ (g adsorbent $) /\left(\mathrm{m}^{2}\right.$ of pipe surface area). This value was used to convert previously reported experimental adsorption densities to units relevant to larger scale modelsspecifically, to help guide the selection of a reasonable value for $S_{\max }$. The reported mass corresponds to the average of the masses of the corrosion materials that were formed throughout conditioning and testing phases of this experiment. This factor is applicable to pipes with a uniform, thin layer of corrosion; pipes with large tubercles or mineral deposits may have a different active surface area per pipe surface area. For this work, a value of $500 \mathrm{mg} / \mathrm{m}^{2}$ was selected for $S_{\max }$. This value of was $\mathrm{S}_{\text {max }}$ was reasonable because it exceeded any adsorbed surface densities that were experimentally measured, however, due to iron's high affinity for As, $S_{\max }$ could be greater than 8,000 $\mathrm{mg} / \mathrm{m}^{2}$ (reported as $13,650 \mu \mathrm{g}$ As/g sample). ${ }^{46} S_{\text {max }}$ values for adsorption onto pipe walls will likely be less than granular adsorption due to the reduction in accessible surface area to adsorption on pipes.

\section{References}

[1] U. S. EPA, Arsenic compounds (December 2012). URL https : //www3.epa.gov/airtoxics/hlthef/arsenic.html

[2] U. S. EPA, Drinking water arsenic rule history (November 2015). URL https://www.epa.gov/dwreginfo/drinking-waterarsenic-rule-history

[3] M. L. Pierce, C. B. Moore, Adsorption of arsenite on amorphous iron hydroxide from dilute aqueous solution, Environmental Science \& Technology 14 (1980) 214-216.

[4] M. L. Pierce, C. B. Moore, Adsorption of arsenite and arsenate on amorphous iron hydroxide, Water Research 16 (1982) 1247-1253.

[5] P. Lakshmipathiraj, B. R. V. Narasimhan, S. Prabhakar, G. Bhaskar Raju, Adsorption of arsenate on synthetic goethite from aqueous solutions, Journal of Hazardous Materials B136 (2006) 281-287.

[6] Adsorbent treatment technologies for arsenic removal, Tech. rep., Awwa Research Foundation (2005).

[7] K. Banerjee, G. L. Amy, M. Prevost, S. Nour, M. Jekel, P. M. Gallagher, C. D. Blumenschein, Kinetic and thermodynamic aspects of adsorption of arsenic onto granular ferric hydroxide (GFH), Water Research 42 (2008) 3371-3378.

[8] C. C. Fuller, J. A. Davis, G. A. Waychunas, Surface chemistry of ferrihydrite: Part 2. Kinetics of arsenate adsorption and coprecipitation, Geochimica et Cosmochimica Acta 57 (1993) 2271-2282.

[9] Z. Zhao, Y. Jia, L. Xu, S. Zhao, Adsorption and heterogeneous oxidation of As(III) on ferrihydrite, Water Research 45 (2011) 6496-6504.

[10] S. Goldberg, C. T. Johnston, Mechanisms of arsenic adsorption on amorphous oxides evaluated using macroscopic measurements, vibrational spectroscopy and surface complexation modeling, Journal of Colloid and Interface Science 234 (2001) 204-216.

[11] S. Goldberg, Competitive adsorption of arsenite and arsenate on oxides and clay minerals, Soil Science Society of America Journal 66 (2002) 413-421.

[12] S. Dixit, J. G. Hering, Comparison of $\operatorname{arsenic}(\mathrm{V})$ and arsenic(III) sorption onto iron oxide minerals: Implications for arsenic mobility, Environmental Science \& Technology 37 (2003) 4182-4189.

[13] S. E. O'Reilly, D. G. Strawn, D. L. Sparks, Residence time effects on arsenate adsorption/desorption mechanisms on goethite, Soil Science Society of America Journal 65 (2001) 67-77.

[14] Y. Mamindy-Pajany, C. Hurel, M. Marmier, M. Roméo, Arsenic adsorption onto hematite and goethite, Comptes Rendus Chimie 12 (2009) 876881 .
[15] Y. Masue, R. H. Loeppert, T. A. Kramer, Arsenate and arsenite adorption and desorption behavior on coprecipitated aluminum:iron hydroxides, Environmental Science \& Technology 41 (2007) 837-842.

[16] B. Lafferty, R. H. Loeppert, Methyl arsenic adsorption and desorption behavior on iron oxides, Environmental Science \& Technology 39 (2005) 2120-2127.

[17] H. Wingrich, C. Wolf, Research on the removal of arsenic from drinking water by flocculation with iron solutions and adsorption with granulated iron hydroxide (GEH), Journal of Water Supply: Research and Technology-AQUA 51 (5) (2002) 273-281.

[18] N. Bhandari, R. J. Reeder, D. R. Strongin, Photoinduced oxidation of arsenite to arsenate ni the presence of goethite, Environmental Science \& Technology 46 (2012) 8044-8051.

[19] K. B. Payne, T. M. Abdel-Fattah, Adorption of arsenate and arsenite by iron-treated activated carbon and zeolites: Effects of $\mathrm{pH}$, temperature, and ionic strength, Journal of Environmental Science and Health 40 (2005) 723-749.

[20] A. Jain, K. P. Raven, R. H. Loeppert, Arsenite and arsenate adsorption on ferrihydrite: Surface charge reduction and net $\mathrm{OH}^{-}$release stoichiometry, Environmental Science \& Technology 33 (1999) 1179-1184.

[21] V. Lenoble, O. Bouras, V. Deluchat, B. Serpaud, J.-C. Bollinger, Arsenic adsorption onto pillared clays and iron oxides, Journal of Colloid and Interface Science 255 (1) (2002) $52-58$.

[22] C. A. Impellitteri, K. G. Scheckel, The distribution, solid-phase speciation, and desorption/dissolution of As in waste iron-based drinking water treatment residuals, Chemosphere 64 (2006) 875-880. doi:10.1016/j.chemosphere.2006.02.001.

[23] C. A. Waltham, M. J. Eick, Kinetics of arsenic adsorption on goethite in the presence of sorbed silicic acid, Soil Science Society of America Journal 66 (2002) 818-825.

[24] K. P. Raven, A. Jain, R. H. Loeppert, Arsenite and arsenate adsorption on ferrihydrite: Kinetics, equilibrium, and adsoprtion evelopes, Environmental Science \& Technology 32 (1998) 344-349.

[25] G. P. Jeppu, T. P. Clement, M. O. Barnett, K.-K. Lee, A scalable surface complexation modeling framework for predicting arsenate adsorption on goethite-coated sands, Environmental Engineering Science 27 (2010) 147-158.

[26] X.-H. Guan, J. Wang, C. C. Chusuei, Removal of arsenic from water using granular ferric hydroxide: Macroscopic and microscopic studies, Journal of Hazardous Materials 156 (2008) 178-185.

[27] M. Habuda-Stanić, B. Kalajdžic, M. Kuleš, N. Velić, Arsenite and arsenate sorption by hydrous ferric oxide/polymeric material, Desalination 229 (2008) 1-9.

[28] W. Driehaus, M. Jekel, U. Hildebrandt, Granular ferric hydroxide-a new adsorbent for the removal of arsenic from natural waters, Journal of Water Supply: Research and Technology-AQUA 47 (1) (1998) 30-35.

[29] G. P. Jeppu, T. P. Clement, A modified Langmuir-Freundlich isotherm model for simulating $\mathrm{pH}$-dependent adsorption effects, Journal of Contaminant Hydrology 129-130 (2012) 46-53.

[30] J. G. Catalano, Y. Luo, B. Otemuyiwa, Effect of aqueous fe(II) on arsenate sorption on goethite and hematite, Environmental Science \& Technology 45 (2011) 8826-8833.

[31] P. R. Grossl, M. Eick, D. L. Sparks, S. Goldberg, C. C. Ainsworth, Arsenate and chromate retention mechanisms on goethite. 2. kinetic evaluation using a pressure-jump relaxation technique, Environmental Science \& Technology 31 (1997) 321-326.

[32] J. T. van Elteren, Z. Šlejkovec, I. Acčon, M. P. Beeston, A. Pohar, Multiple kinetic Langmuir modeling to predict the environmental behaviour of as(V) in soils, Journal of Environmental Monitoring 13 (2001) 16251633.

[33] M. C. Dodd, N. D. Vu, A. Ammann, V. C. Le, R. Kissner, H. V. Pham, T. H. Cao, M. Berg, U. von Gunten, Kinetics and mechanistic aspects of As(III) oxidation by aqueous chlorine, chloramines, and ozone: Relevance to drinking water treatment, Environmental Science \& Technology 40 (2006) 3285-3292.

[34] B. A. Manning, S. E. Fendorf, S. Goldberg, Surface structures and stability of arsenic(III) on goethite: Spectroscopic evidence for inner-sphere complexes, Environmental Science \& Technology 32 (1998) 2383-2388.

[35] S. Fendorf, M. J. Eick, P. Grossl, D. L. Sparks, Arsenate and chromate retention mechanisms on goethite. 1. surface structure, Environmental Science \& Technology 31 (2) (1997) 315-320. 
[36] S. Sorlini, F. Gialdini, Conventional oxidation treatments for the removal of arsenic with chlorine dioxide, hypochlorite, potassium permanganate and monochloramine, Water Research 44 (2010) 5663-5659.

[37] S. Vasudevan, S. Mohan, G. Sozhan, N. S. Raghavendran, C. V. Murugan, Studies on the oxidation of $\mathrm{As}(\mathrm{III})$ to $\mathrm{As}(\mathrm{V})$ by in-situ-generated hypochlorite, Industrial \& Engineering Chemistry Research 45 (2006) 7729-7732.

[38] G. P. Jeppu, T. P. Clement, M. O. Barnett, K.-K. Lee, A modified batch reactor system to study equilibrium-reactive transport problems, Journal of Contaminant Hydrology 129-130 (2012) 2-9.

[39] S. E. Philips, M. L. Taylor, Oxidation of arsenite to arsenate by alcaligenes faecalis, Applied and Environmental Microbiology 32 (1976) 392399.

[40] J.-H. Huang, A. Voegelin, S. A. Pombo, A. Lazzaro, J. Zeyer, R. Kretschmar, Influence of arsenate adsorption to ferrihydrite, goethite, and boehmite on the kinetics of arsenate reduction by Shewanella putrefaciens strain CN-32, Environmental Science \& Technology 45 (2011) 7701-7709.

[41] J.-H. Huang, E. J. Elzinga, Y. Brechbuehl, A. Voegelin, R. Kretzschmar, Impact of Shewanella putrefaciens strain CN-32 cells and extracellular polymeric substances on the sorption of $\mathrm{As}(\mathrm{V})$ and $\mathrm{As}(\mathrm{III})$ on $\mathrm{Fe}(\mathrm{III})$ (hydr)oxides, Environmental Science \& Technology 45 (2011) 28042810.

[42] M. Bissen, F. H. Frimmel, Aresnic - a review. Part II: Oxidation of arsenic and its removal in water treatment, Acta hydrochimica et hydrobiologica 31 (2003) 97-107.

[43] S. J. Hug, L. Canonica, M. Wegelin, D. Gechter, U. von Gunten, Solar oxidation and removal of arsenic at circumneutral $\mathrm{pH}$ in iron containing waters, Environmental Science \& Technology 35 (2001) 2114-2121.

[44] M. Dinesh, C. U. Pittman Jr., Arsenic removal from water/wastewater using adsorbents - a critical review, Journal of Hazardous Materials 142 (2007) 1-53. doi:10.1016/j.jhazmat.2007.01.006.

[45] H. Mohebbi, C. Q. Li, Experimental investigation on corrosion of cast iron pipes, International Journal of Corrosion 2011 (2011) Article ID 506501, 17 pages.

[46] D. A. Lytle, T. J. Sorg, C. Frietch, Accumulation of arsenic in drinking water distribution systems, Environmental Science \& Technology 38 (2004) 5365-5372.

[47] D. A. Lytle, T. Sorg, L. Wang, A. Chen, The accumulation of radioactive contaminants in drinking water systems, Water Research 50 (2014) 396407.

[48] T. L. Gerke, J. B. Maynard, M. R. Schock, D. L. Lytle, Physiochemical characterization of five iron tubercles from a single drinking water distribution system: Possible new insights on their formation and growth, Corrosion Science 50 (2008) 2030-2039.

[49] D. A. Lytle, T. J. Sorg, C. Muhlen, L. Wang, Particulate arsenic release in a drinking water distribution system, Journal of the American Water Works Association 102 (3) (2010) 87-98.

[50] S. A. Crosby, D. R. Glasson, A. H. Cuttler, I. Butler, D. R. Turner, M. Whitfield, G. E. Millward, Surface areas and porosities of Fe(III)and Fe(II)-derived oxyhydroxides, Environmental Science \& Technology 17 (1983) 709-713.

[51] F. Shang, J. G. Uber, L. A. Rossman, EPANET Multi-Species Extension: User's Manual, EPA/600/S-07/021 (2011).

[52] F. Shang, J. G. Uber, L. A. Rossman, Modeling reaction and transport of multiple species in water distribution systems, Environmental Science \& Technology 42 (2008) 808-814.

[53] L. A. Rossman, EPANET 2: Users Manual, EPA/600/R-00/057 (2000),

[54] S. T. Klosterman, J. G. Uber, R. Murray, D. Boccelli, Adsorption model for arsenate transport in corroded iron pipes with application to a simulated intrusion in a water distribution network, Journal of Water Resources Planning and Management 140 (2014) 649-657.

[55] S. Klosterman, R. Murray, J. Szabo, J. Hall, J. Uber, in: Modeling and simulation of arsenate fate and transport in a distribution system simulator, 2010, Water Distribution System Analysis, Tucson, AZ.

[56] J. Hagar, R. Murray, T. Haxton, J. Hall, J. Szabo, in: Predicting Arsenic Intrusion in a Drinking Water Distribution System: Implications for Decontamination, 2011, AWWA Water Quality Technology Conference, Phoenix, AZ.

[57] L. Monteiro, D. Figueiredo, S. Dias, R. Freitas, D. Covas, J. Menaia, S. T. Coelho, Modeling of chlorine decay in drinking water supply systems using EPANET MSX, Procedia Engineering 70 (2014) 1192-1200.

[58] N. Ratnayake, I. N. Jayatiake, Study of transport of contaminants in a pipe network using the model EPANET, Water Science and Technology 40 (1999) 115-120

[59] J. Muranho, A. Ferreira, J. Sousa, A. Gomes, A. Sá Marques, Technical performance evaluation of water distribution networks based on EPANET, Procedia Engineering 70 (2014) 1201-1210.

[60] A.-M. Georgescu, S. Perju, S.-C. Georgescu, A. Anton, Numerical model of a district water distribution system in Bucharest, Procedia Engineering 70 (2014) 707-714.

[61] U.S. EPA, Pilot-Scale Tests and Systems Evaluation for the Containment, Treatment, and Decontamination of Selected Materials From T\&E Building Pipe Loop Equipment, EPA/600/R-08/016 (2008).

[62] U.S. EPA, Chemical Contaminant Persistence and Decontamination in Drinking Water Pipes: Results using the EPA Standardized Persistence and Decontamination Experimental Design Protocol, EPA/600/R/12/514 (2012).

[63] L. S. Clesceri, A. E. Greenberg, A. D. Eaton, Standard Methods for the Examination of Water and Wastewater, 20th ed., published jointly by the American Public Health Association, American Water Works Association, and the Water Environment Federation, Washington, DC, 1998.

[64] L. K. Koopal, M. J. Avena, A simple model for adsorption kinetics at charged solid-liquid interfaces, Colloids and Surfaces 192 (2001) 93-107.

[65] E. L. Cussler, Diffusion: Mass transfer in fluid systems, 1st Edition, Press Syndicate of the University of Cambridge, New York, NY, 1984.

[66] M. Tanaka, Y. Takahashi, N. Yamaguchi, K.-W. Kim, G. Zheng, M. Sakamitsu, The difference of diffusion coefficients in water for arsenic compounds at various $\mathrm{pH}$ and its dominant factors implied by molecular simulations, Geochimica et Comsochimica Acta 105 (2013) 360-371.

[67] N. E. Korte, Q. Fernando, A review of arsenic (III) in groundwater, Critical Reviews in Environmental Control 21 (1991) 1-39.

[68] R. C. Copeland, D. A. Lytle, D. D. Dionysiou, Desorption of arsenic from drinking water distribution system solids, Environmental Monitoring and Assessment 127 (2007) 523-535.

[69] D. A. Lytle, M. L. Magnuson, V. L. Snoeyink, Effect of oxidants on the properties of $\mathrm{Fe}$ (III) particles and suspensions formed from the oxidation of Fe(II), Journal of the American Water Works of America 98 (8) (2004) $112-124$. 